\title{
Ergonomic evaluation of novel tool for snap-off the neck of ampoule
}

\author{
Bor-Shong Liu ${ }^{\mathrm{a},}{ }^{*}$, Jun-Ting Lee ${ }^{\mathrm{b}}$ and Ching-Wen Lien ${ }^{\mathrm{c}}$ \\ ${ }^{a}$ Department of Industrial Engineering and Management, St. John's University, New Taipei City, 25135, TAIWAN \\ ${ }^{\mathrm{b}}$ Taipei Hospital, Department of Health, New Taipei City, 24213, TAIWAN \\ ${ }^{\mathrm{c}}$ Nursing Department, Taipei Veterans General Hospital, Taipei, 11217, TAIWAN
}

\begin{abstract}
Needlestick and Sharps Injuries (NSI) represent an important workplace issue in contemporary health care. Present study provided the new method to snap-off the neck of sealed ampoule. The idea of novel opener tool is prepare the grinding slice inside rubber ring, so users could put the ampoule inside the rubber ring and then rotated the rubber ring to snap-off the neck of ampoule. The purpose of present study was evaluated the methods of snap-off and sizes of ampoule on forearm muscle activities, wrist postures and performance. The pronator teres muscle were heavier load as increased the sizes of ampoule. For performance analysis, Duncan's multiple range tests indicated that time of snap-off were longer in $10 \mathrm{ml}$ and $20 \mathrm{ml}$ of ampoule. The EMG of pronator teres muscle was significantly affected by methods of snap-off. Duncan's multiple range tests indicated that lower load was experienced on forearm muscles while using grinding slice with glove. For wrist posture, the ranges of motion for wrist were significant lower while using the novel tool. Present study provided the novel tool effectively to snap-off the ampoule to decrease forearm workload and sharp injuries.
\end{abstract}

Keywords: needlestick and sharps injuries, ampoule, occupational safety and health, product design, EMG

\section{Introduction}

Unsafe injection practices place at risk not only patients, but also healthcare workers, who practice universal precautions inconsistently and are commonly exposed to blood in the course of their work [11]. Several approaches to the promotion of injection safety have been suggested, including the widespread use of auto-disable syringes (WHO) and IEC (information, education, communication) campaigns to make patients more informed consumers of healthcare services [3, 15]. However, these approaches have limitations.

In addition, needlestick injuries are an occupational hazard for health care professionals, particularly nurses. The Centers for Disease Control and Prevention has estimated that health care professionals suffer between 600,000 and 1 million injuries from conventional needles and sharps annually in the United States, and that $\geq 1000$ health care professionals contract serious infections annually from needlestick and sharps injuries [1]. Based on statistical studying Taiwan, 527 nursing students under clinical tranning, the prevalence of percutaneous injuries and injuries with blood exposure accidents (BEAs) was 50.1\% and $18.2 \%$, respectively [16]. Further, the most cases for sharp injuries were opening ampoules [9].

The study compared the risk of needlestick injury with NFA (NovoFine Autocover) needles and regular needles on insulin pens among nurses who administered insulin to patients [12]. A total of 143 nurses at 52 hospitals located throughout France received training. No needlestick injuries occurred with NFA needles, whereas 1 needlestick injury occurred with a regular needle. Nurses were very satisfied with the NFA needles, giving them a score of 8.1 on a scale of 0 to 10 , rating personal safety as a particularly important benefit (score 9.5). Nurses preferred NFA needles to both regular needles on insulin pens and needles on syringes, citing personal safety and the saving of time as the main reasons.

\footnotetext{
*Corresponding author. E-mail: bsliu@mail.edu.tw.
} 
For clinical nursing, injection drugs with chemical properties that are more stable in glass, are mostly supplied in bottles or vials, especially ampoules. Nurses must snap off the neck of sealed ampoule and aspirate the solution inside it with a syringe before an injection. However, the zigzag glass surface on the neck of the ampoule often cuts the hands of nurses while preparing the drug. Present study provided the new method to snap off the neck of sealed ampoule. Thus, the purpose of present study was evaluated the methods of snap-off and sizes of ampoule on forearm muscle activities, wrist postures and performance.

\section{Methods}

\subsection{Participants}

Ten nurses and emergency medical technician were recruited in present study. All subjects were healthy and reported no musculoskeletal problems that might influence performance detrimentally.

\subsection{Apparatus and materials}

Each subject performed 75 combinations of snapoff the neck of sealed ampoule at three methods (i.e., grinding slice, grinding slice with gloves and novel tool) and five sizes of ampoule ( $1 \mathrm{ml}, 2 \mathrm{ml}, 5 \mathrm{ml}, 10$ $\mathrm{ml}$ and $20 \mathrm{ml}$ ) for five repetition (Figure 1 and Figure 2 ). The idea of novel opener tool is prepare the grinding slice inside rubber ring, so users could put the ampoule inside the rubber ring and then rotated the rubber ring to snap-off the neck of ampoule.

Electromyography (EMG) activities of the target muscle groups were recorded by means of bipolar direct measurements (MP150, Biopac Systems Inc, California, USA). Pairs of $\mathrm{Ag} / \mathrm{AgCl}$ surface electrodes (Blue Sensor M-00-S, Medicotest, Ballerup, Denmark) separated by $20 \mathrm{~mm}$ were placed on Pronator Teres of dominantly hand. The signals were amplified, the band-pass was filtered at $20-500 \mathrm{~Hz}$, and the $\mathrm{A} / \mathrm{D}$ was converted and sampled at $1000 \mathrm{~Hz}$. Reference voluntary contraction for normalization was obtained during maximum isometric voluntary contraction (MVC) of the specific muscle group for two trials of approximately 5 seconds each.

In addition, the miniature joint angle sensor (S720, Measurand Inc., Canada) had been mounted on the neutral axis of wrist. Further, wrist angles have been measured during experiment.

\subsection{Data analysis}

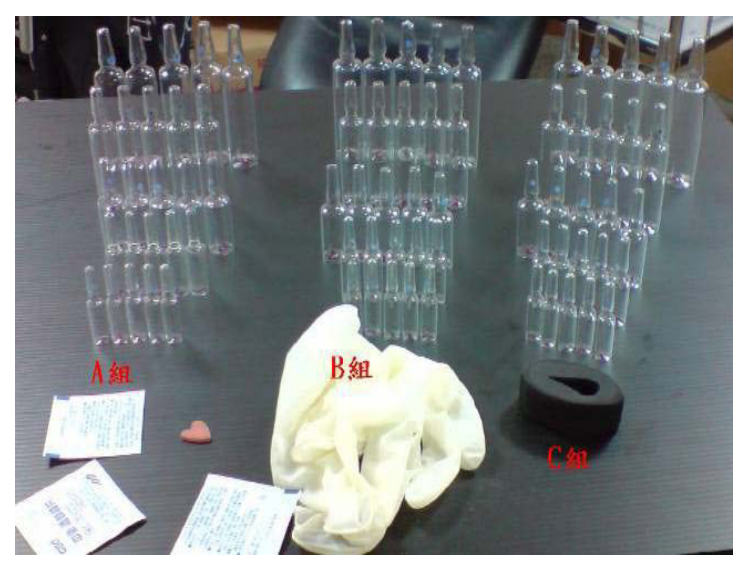

Figure 1

The trials of the 75 combinations
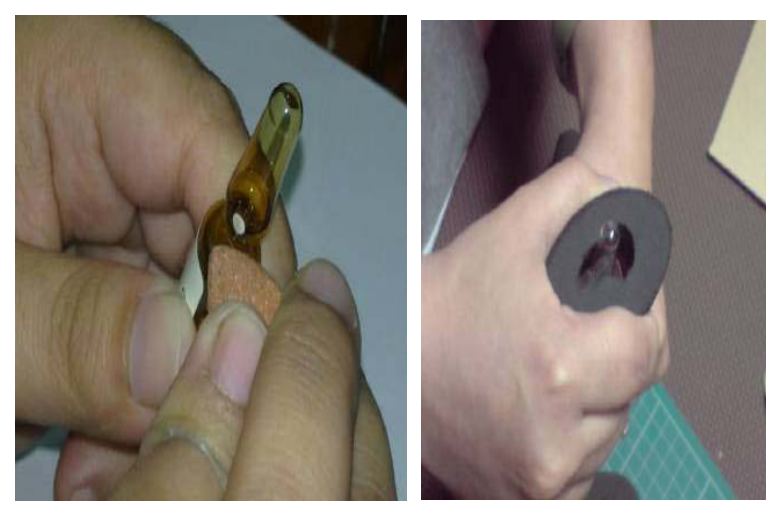

Figure 2

Two methods for snap-off the neck of ampoule

A factorial design with block factor (participants) and two factors (sizes of ampoule and methods of snap-off) was applied in present study. The dependent variables were angles of wrist, EMG (\%) for Pronator Teres and time (sec). Further, analysis of variance (ANOVA) was utilized to identify significant differences between conditions for dependent variables. Statistical significance was set at a probability level of 0.05 . Where statistically significant differences were identified, the Duncan post hoc test was used to examine the differences.

\section{Results}

\subsection{Effects of ampoule sizes}

Results of ANOVA showed that these were significantly differences between ampoule sizes in EMG of 
Pronator Teres $(\mathrm{F}(4,126)=17.5, \mathrm{p}<0.001)$ and time $(\mathrm{F}(4,126)=6.4, \mathrm{p}<0.001)$.

The pronator teres muscle were heavier load as increased the sizes of ampoule. These are $67 \%, 62 \%$, $54 \%, 46 \%$ and $45 \%$ of maximum isometric voluntary contraction (MVC) for $20 \mathrm{ml}, 10 \mathrm{ml}, 5 \mathrm{ml}, 2 \mathrm{ml}$, and $1 \mathrm{ml}$ of ampoule respectively (Figure 3 ). The mean wrist flexion angles were not significant difference between sizes of ampoule.

For performance analysis, Duncan's multiple range test indicated that time of snap-off were longer in $10 \mathrm{ml}$ and $20 \mathrm{ml}$ of ampoule (Figure 4).

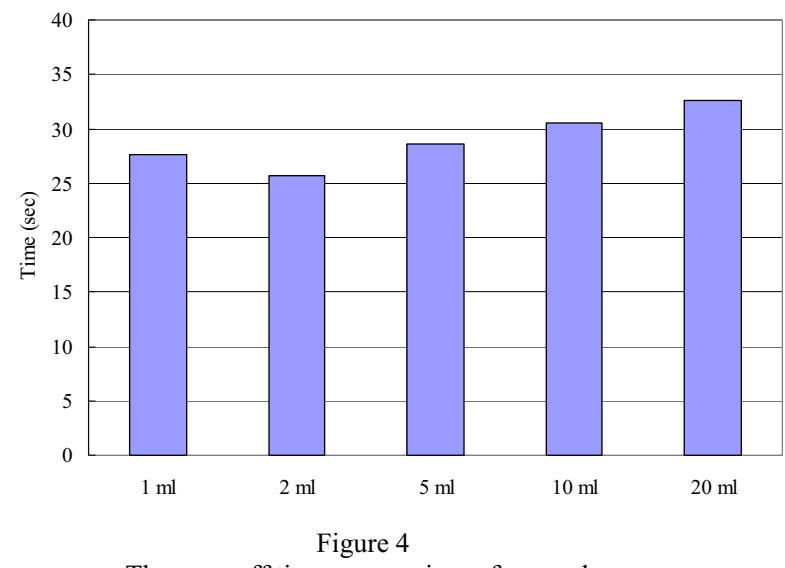

The snap-off time among sizes of ampoule

\subsection{Effects of snap-off methods}

Results of ANOVA showed that these were significantly differences between snap-off methods in EMG of Pronator Teres $(F(2,126)=2.98, p<0.05)$, wrist angles $(\mathrm{F}(2,126)=15.3, \mathrm{p}<0.001)$ and time $(\mathrm{F}(4,126)=6.4, \mathrm{p}<0.001)$.

The EMG of pronator teres muscle was significantly affected by methods of snap-off. Duncan's multiple range tests indicated that lower load was experienced on forearm muscles while using grinding slice with glove. For wrist posture, the ranges of motion for wrist were significant lower while using the novel tool. In addition, range of motion for wrist angles were 62 degrees, 73 degrees, and 80 degrees in using novel tool, grinding slice and grinding slice with glove respectively (Figure 5). For performance analysis (Figure 6), mean time of snap-off was better significantly while using novel tool $(20 \mathrm{sec})$ than in using grinding slice with glove $(31 \mathrm{sec})$ and grinding slice only $(35 \mathrm{sec})$.

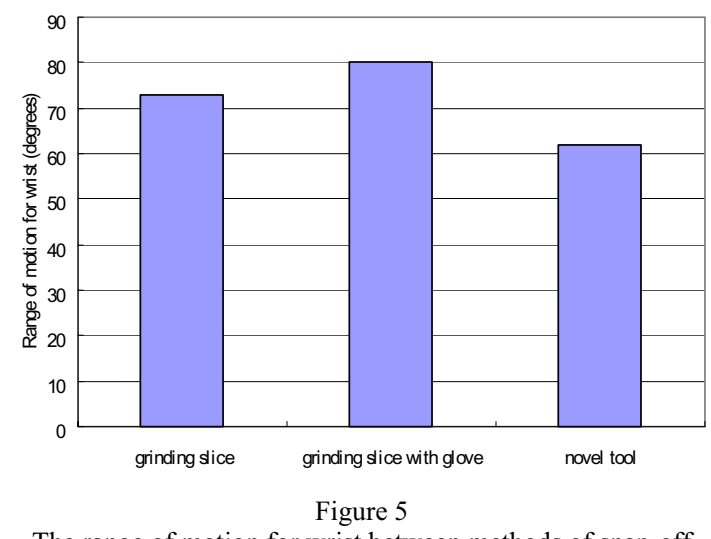

The range of motion for wrist between methods of snap-off

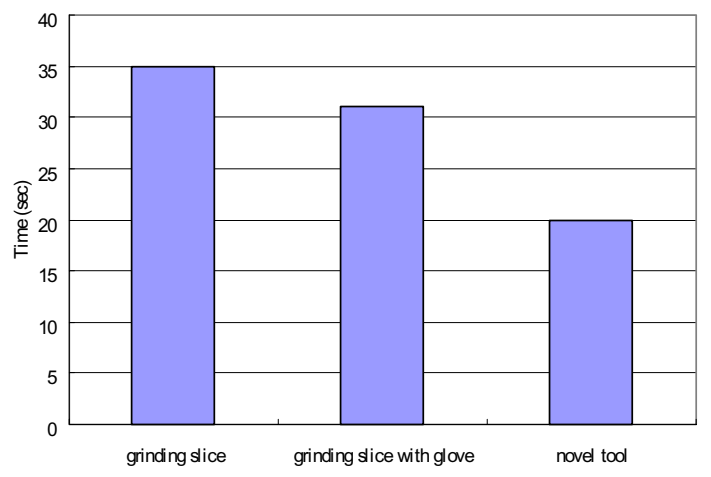

Figure 6

The operating time between methods of snap-off

\section{Discussion}

Percutaneous exposure incidents (PEI) are a broaddescriptive term that includes needlestick and sharps injuries, as well as cutaneous and mucous exposures to blood and serum. Smith et al. [7] investigated all reported percutaneous exposure incidents among staff from a large Australian hospital in the 3year period, 2001-2003. There were a total of 373 PEI, of which $38.9 \%$ were needlestick injuries, $32.7 \%$ were cutaneous exposures and $28.4 \%$ sharpsrelated injuries. Sharps injuries in the operating theatre setting expose personnel to human immunodeficiency virus (HIV), hepatitis B virus (HBV), and hepatitis $\mathrm{C}$ virus (HCV). Hagstrom [2] mention that a study published in 2001 which is found 54 documented cases of medical personnel in the United States and Canada who had contracted HIV as a result of needle stick injuries or other exposure. The 
rate of needle sticks and sharps injuries reported in the United States ranges from 380,000 to 500,000 per year.

Needlestick and Sharps Injuries (NSI) represent an important workplace issue in contemporary health care. Australian study for example Peggat [14], NSI as a cause of injury among nurses was exceeded only by musculoskeletal injuries. In a study of Chinese nurses [6], almost all had experienced at least one NSI in their professional lifetime. Another Japanese study conducted in 2004 also found that ampoules or vials, hollow bore needles and insulin needles were common causes of needlestick and sharps Injuries [8] Similar to results, research from Turkey [15], Australia [7], Singapore [10], Taiwan [17], and Korea [5] has indicated that disposable syringes and medication ampoules continue to present NSI risks for Health Care Workers.

Results of analysis for risk factors of sharp injury showed that $36.9 \%$ of nurses had suffered sharp injury. The risk factors to sharp injuries were opening the glass ampoule with gauze and lack of the standardamploue precautions. The main risk factors leading to the sharp injuries were mistakes or deficiencies in operation. Thus, present study provided the novel tool effectively to snap-off the ampoule. In addition, results of EMG and wrist postures suggest that novel tool could reduce the risk of needlestick injuries, such as ease of use and saving of time. However, the class particles contamination in ampoule should be examined in further study.

\section{References}

[1] American Association of Diabetes Educators. Insulin selfadministration instruction: Use of engineered sharps injury protection devices to meet OSHA regulations. Diabetes Education 28 (2002), 730-734.

[2] A.M. Hagstrom, Perceived barriers to implementation of a successful sharps safety program, AORN Journal 83 (2006), 391-396.

[3] D. Gisselquist, E. Friedman, J.J. Potterat, S.F. Minkin, and S. Brody, Four policies to reduce HIV transmission through unsterile health care, International Journal of STD AIDS 14 (2003), 717-722.

[4] D.R. Smith, M. Mihashi, Y. Adachi, Y. Nagashima, T. Ishitake, Epidemiology of needlestick asnd sharps injuries among nurses in a Japanese teaching hospital, Journal of Hospital Infection 64 (2006), 44-49.

[5] D.R. Smith, M.A. Choe, J.S. Jeong, M.Y. Jeon, Y.R. Chae, and G.J. An. (2006). Epidemiology of needlestick and sharps injuries among professional Korean nurses. Journal of Professional Nurse 22 (2006), 359-366.

[6] D.R. Smith, N. Wei, R.S. Wang, Needlesticks and sharps injuries among Chinese hospital nurses, Advances in Exposure Prevention 7 (2004), 11-12.
[7] D.R. Smith, P.A. Leggat, K. Takahashi, Percutaneous exposure incidents among Australian hospital staff, International Journal of Occupational Safety and Ergonomics 11, (2005), 323-330.

[8] D.R. Smith, T. Muto, T. Sairenchi, Y. Ishikawa, S. Sayama, A. Yoshida and M. Townley-Jones, Hospital safety climate, psychosocial risk factors and needlestick injuries in Japan, Industrial Health 48 (2010), 85-95.

[9] J.D. Lee, The study of safety ampoule opener design and evaluation, Master Dissertation, St. John's University, 2010.

[10]L.N. Ng, H.L. Lim, Y.H. Chen, D. Bin Bachok, Analysis of sharps injury occurrences at a hospital in Singapore, International Journal of Nursing Practice 8 (2002), 274-281.

[11] M. Kermode, Healthcare worker safety is a pre-requisite for injection safety in developing countries, International Journal of Infectious Diseases 8 (2004), 325-327.

[12] O. Lautier, H. Mosnier-Pudar, D. Durain, S. Gonbert, L. Spinu and $\mathrm{P}$. Faure, Risk of needlestick injuries among nurses using NovoFine Autocover safety needles and nurses' satisfaction with the needles: the NOVAC study, Insulin 3 (2008), 232237.

[13]U. Ayranci, and N. Kosgeroglu, Needlestick and sharps injuries among nurses in the healthcare sector in a city of western Turkey. American Journal of Infection Control 58 (2004), 216-223.

[14]P.A. Leggat, Microbiological hazards posed by 'sharps': complications of needle puncture injuries to nurses, Australian Microbiologist 8 (1987), 311-4.

[15] WHO-UNICEF-UNFPA Joint statement on the use of autodisable syringes in immunization services. December 1999.

[16] Y. H. Yang, The needlestick/sharp injuries and its' effects of intervention among nursing students, Master Dissertation, Kaohsiung Medical University, 2001.

[17] Y.L. Guo, J. Shiao, Y.C. Chuang, K.Y. Huang, Needlestick and sharps injuries among health-care workers in Taiwan, Epidemiology infection 122 (1999), 256-265. 